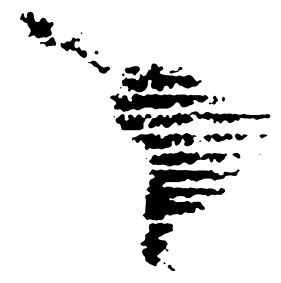

\title{
UNA MIRADA DE GÉNERO A LOS DERECHOS HUMANOS DE LAS MUJERES PRIVADAS DE LIBERTAD EN VENEZUELA
}

\author{
Dhayana Carolina Fernández Matos*
}

\section{Resumen}

Este artículo busca dar a conocer la situación de los derechos humanos de las mujeres privadas de libertad en Venezuela mediante un enfoque de género para explicar sus necesidades y experiencias de vida, que son invisibilizadas por el sistema carcelario que reproduce los roles de género, profundizando la discriminación y violación de derechos, generándose situaciones de exclusión que atentan contra la dignidad humana. Las mujeres que se encuentran privadas de libertad son titulares de derechos en las mismas condiciones en que están las personas que se encuentran en libertad, más allá de los derechos específicos que priva la sentencia condenatoria, siendo mayor la obligación del Estado de garantizar el disfrute de los mismos al tratarse de personas que se encuentran bajo su tutela jurídica.

Palabras clave: mujeres privadas de libertad, género, derechos humanos, Venezuela.

\section{Abstract}

This article seeks to publicize the situation of human rights of women deprived of freedom in Venezuela through a gender approach to visualize their needs and life experiences, which are invisible by the prison system that reproduces gender roles, deepening discrimination and violation of rights, generating exclusion situations that threaten human dignity. Women who are deprived of their liberty have human rights beyond the rights which the sentence deprives, being greater the state's obligation to protect them.

Keywords: women deprived of freedom, gender, human rights, Venezuela.

* Abogada (Universidad Católica Andrés Bello, Venezuela), Licenciada en Ciencias Políticas y Administrativas (Universidad Central de Venezuela), Magíster en Ciencia Política y de la Administración (Universidad Autónoma de Barcelona, España), Maestría Oficial en Género, Identidad y Ciudadanía (Universidad de Cádiz, España) y Magíster en Derechos Humanos, Estado de Derecho y Democracia en Iberoamérica (Universidad de Alcalá, España). Profesora de la Universidad Central de Venezuela y de la Escuela Nacional de la Magistratura. 
La situación carcelaria en Venezuela presenta graves problemas que quebrantan diariamente los derechos humanos de las personas privadas de libertad, entre ellos destacan el hacinamiento; la falta de medidas higiénicas y sanitarias que permitan a las internas y a los internos vivir en condiciones que no atenten contra su dignidad; el aumento del número de procesadas y procesados en comparación con el número de condenadas y condenados y, principalmente, la cantidad de reclusos (hombres) que son asesinados anualmente en los centros de reclusión, ya que la violencia en las cárceles se ha convertido en un problema estructural del sistema penitenciario venezolano.

Según cifras obtenidas del Programa Venezolano de Educación-Acción en Derechos Humanos (Provea) el número de muertes violentas dentro de los recintos carcelarios fue de 412 personas en 2006; 498 en 2007 y para el año 2012, según información hemerográfica y no las cifras oficiales, se estima que 241 personas privadas de libertad perdieron la vida en recintos carcelarios, en este último año se incluye una mujer del Internado Judicial de San Juan de los Morros asesinada con un arma blanca (Provea, 2012). Para el primer semestre del año 2013, el Observatorio Venezolano de Prisiones denunció que murieron 289 internos y 423 resultaron heridos, lo que implica que hubo más de un muerto por día en las cárceles venezolanas.
Pese a que son muchos los problemas existentes en los centros penitenciarios de Venezuela, este trabajo se centra en la invisibilización absoluta de las mujeres privadas de libertad en los programas y políticas carcelarias que desarrolla o procura desarrollar el gobierno venezolano, así como la discriminación de la cual son víctimas en el goce y ejercicio de sus derechos. Se pretende justificar esta situación argumentando que se trata de un porcentaje muy inferior al de los hombres privados de libertad; en ese sentido, se estima que el número de personas privadas de libertad en Venezuela para el año 2012 es de 45.224, de las cuales 2.400 son mujeres, representando $5,30 \%$ de la población total. Estos porcentajes se asemejan a los existentes en otros países de América Latina donde el número de mujeres está entre el $4 \%$ y el $9 \%$, a excepción de Bolivia donde las mujeres representan el 20\% de la población penitenciaria (Rodríguez, 2004).

Pero la verdadera razón de esta invisibilización es que existe la visión androcéntrica que asume como modelo al hombre y tiene como referencia a los reclusos, siendo las reclusas solo un componente residual sin que existan medidas específicas que respondan a sus propias experiencias como mujeres. Se plantean, incluso, razones de orden y seguridad, argumentando que, en virtud de que las reclusas pocas veces hacen uso de la fuerza, se fugan, se amotinan o representan un grave riesgo para la seguridad de las prisiones, su 
situación particular no es vista como prioritaria y sus demandas tienden a postergarse por tiempo indefinido (Azaola, 2007).

Es preciso reconocer los elementos de la cultura androcéntrica y patriarcal que siguen presentes en los centros penitenciarios, reproduciendo las condiciones de discriminación de la mujer en el ejercicio de sus derechos, reproduciendo, además, los roles de género inclusive en los cursos y talleres de formación profesional impartidos a hombres y mujeres, lo que, sin duda, marcará sus posibilidades reales de inserción social y laboral una vez cumplida la pena impuesta. Para explicar este punto y también para ubicarnos en el contexto general, haremos referencia a entrevistas realizadas a funcionarios, funcionarias, hombres recluidos y mujeres recluidas en el Centro Penitenciario Región Centro Occidental (Uribana) del estado Lara, así como a fuentes secundarias referentes a investigaciones en este temática realizadas en otros centros penitenciarios de Venezuela.

Este trabajo se plantea bajo la óptica de una investigación cualitativa género sensitiva, no porque se refiera explícitamente a mujeres sino porque toma en cuenta el género para explicar cómo las relaciones asimétricas de poder entre hombres y mujeres fundadas en las diferencias sexuales y en la construcción social de la identidad a partir de dichas diferencias afectan el ejercicio de los derechos humanos y la toma de decisiones de las mujeres privadas de libertad. Se persigue conocer y hacer visible la realidad de estas mujeres, sus necesidades, experiencias y trayectorias de vida, para ponerle al estudio un rostro humano de mujer.

Además, se trata de una investigación descriptiva y analítica, ya que su objetivo fundamental consiste en caracterizar y analizar la situación social e indagar en los derechos humanos de las mujeres privadas de libertad en sus rasgos más peculiares o diferenciadores.

El interés de abordar la problemática de los derechos humanos de las mujeres privadas de libertad se debe a que siempre son las "últimas de las filas" en los programas implementados para hacer frente a la grave situación carcelaria venezolana, hasta el punto que, incluso, resulta difícil conseguir referencia expresa a las reclusas en las actividades de las organizaciones no gubernamentales que abordan esta temática y en investigaciones académicas, muchas de las cuales no poseen la perspectiva de género, elemento fundamental para poder apreciar las vivencias, experiencias y necesidades de las reclusas.

Por otra parte, esta forma de abordar la crisis carcelaria no toma en cuenta la violencia de la cual son objeto las reclusas por parte de funcionarios que laboran en los penales, los efectivos de la Guardia Nacional y demás agentes del Estado que, en principio, deberían garantizar el respeto de sus derechos humanos. 
En este documento se busca exponer, en primer lugar, los elementos teóricos para la realización de un análisis de género, después, el contexto general y la situación de las mujeres reclusas, haciéndose referencia al marco normativo en materia de derechos humanos, incluyendo los derechos sexuales y reproductivos.

\section{El género como categoría de análisis}

En el año 1975, la antropóloga estadounidense Gayle Rubin, en su artículo El tráfico de mujeres: Notas sobre la "economía política" del sexo (1986) define el sistema sexo-género como "el conjunto de disposiciones por el que una sociedad transforma la sexualidad biológica en producto de la actividad humana, y en el cual se satisfacen esas necesidades humanas transformadas" (p.97).

Y de esa manera queda establecido que el género no es sinónimo de mujer, se trata de la construcción social de la identidad a partir de las diferencias sexuales, lo cual afecta la distribución de bienes materiales o simbólicos, la asignación de roles y tareas, la división sexual del trabajo y, en general, todas las esferas del accionar humano. El uso del género como categoría de análisis ha sido impulsado por la necesidad de visibilizar a las mujeres que durante mucho tiempo han sido (y aún siguen siendo) invisibilizadas, fenómeno del cual no escapa la realidad carcelaria venezolana, lo que origina que sus realidades se incluyan en los modelos que tienen como centro del análisis a los hombres, operando el modelo "hombre" como referente universal de lo que implica el ser humano, dejando a un lado las necesidades de las mujeres lo que repercute en su acceso a bienes, recursos y en el ejercicio integral de sus derechos humanos.

Cabe destacar la necesidad de articular el género "en conjunción con una visión de igualdad política y social que comprende no solo el sexo, sino también la clase y la raza" (Scott, 1996, p. 302). Esta conjunción del género con otras categorías como etnia, origen, clase social, orientación sexual, entre otras, es fundamental en la construcción de las identidades de las mujeres y ha sido uno de los cuestionamientos claves que desde el feminismo postcolonial y el feminismo del tercer mundo se ha hecho a las teorías que pretenden homogeneizar al sujeto mujer, usando como modelo o tipo ideal la mujer blanca, educada y occidental, sin tomar en cuenta cómo la construcción de género se ve permeaba por la etnia, la clase social, el origen, la orientación sexual, las condiciones de pobreza, el VIH, entre otros factores.

En el caso de las mujeres privadas de libertad cobra fuerza la necesidad de indagar en la relación del género con otras categorías de análisis, por ejemplo, el origen étnico, para conocer las situaciones particulares a las cuales pueden verse sometidas las mujeres pertenecientes a pueblos indígenas cuando se enfrentan al sistema carcelario. Es así que en un trabajo 
referente a las mujeres privadas de libertad en la Cárcel de Maracaibo se señala que aproximadamente el $90 \%$ de las mujeres que se encuentran en este recinto penitenciario y que han sido condenadas o procesadas por tráfico, ocultamiento, tenencia y posesión de estupefacientes, son indígenas, pertenecen a la etnia wayuu y no hablan castellano, denunciándose las barreras para el acceso a la justicia y la violación del debido proceso a la cual se han visto sometidas debido a que no se les asignó una persona para que sirviera de traductor o traductora y la imposibilidad real de ser escuchadas (Aponte, 2002).

De igual manera, debe analizarse la condición social, la situación de pobreza y la exclusión que ésta puede generar en el ejercicio de los derechos de las mujeres.

En un trabajo realizado con mujeres del Centro Penitenciario Región Andina del estado Mérida de Venezuela (Tampoa, 2010) se analizan las causas por las cuales las mujeres privadas de libertad se implican en la comisión de un delito, estableciéndose como causa común las carencias económicas, tanto reales como ficticias. Dentro de las carencias económicas reales se señalan la asunción por parte de las mujeres del rol de único sostén del hogar, en muchas ocasiones en una situación de pobreza y exclusión marcada por la falta de acceso a la educación, a la incorporación precaria al mercado laboral, lo que termina abrumándolas y haciéndolas más vulnerables a propuestas lucrativas que cruzan la frontera de la legalidad, es decir, cometiendo delitos. Dentro de las carencias ficticias están la necesidad de independizarse de los padres, de ascender en el estatus social y, principalmente, la necesidad de aceptación y pertenencia a un determinado grupo social. En este último caso, se trata generalmente de mujeres jóvenes, altamente consumistas, que persiguen lograr tener un estilo de vida que se promociona a través de medios de comunicación social comercial.

Usar el género como categoría de análisis ayuda a reconocer las causas que producen desigualdades e inequidades y además, a que se diseñen mecanismos que permitan superar esas brechas, ubicando la problemática no en los hombres o las mujeres como individuos, sino en relaciones sociales construidas sobre el poder y la exclusión. Es así que en este trabajo se pretende hacer visible las múltiples discriminaciones que sufren las mujeres privadas de libertad y la forma como los roles y estereotipos de género marcan su trayectoria vital en los recintos penitenciarios.

Hay que subrayar que la raíz del problema no está en las diferencias, sino en la construcción de un sistema social que a partir de estas, coloca a las mujeres en una situación de desventaja que se traduce en el campo de los derechos humanos como desigualdad, discriminación y violencia basada en género, lo cual en el caso de las 
mujeres privadas de libertad agrava su situación de vulnerabilidad.

Maqueda (2006, p.2) señala que el género se constituye como resultado:

(...) de un proceso de construcción social mediante el que se adjudican simbólicamente las expectativas y valores que cada cultura atribuye a sus varones y mujeres. Fruto de ese aprendizaje cultural de signo machista, unos y otras exhiben los roles e identidades que le han sido asignados bajo la etiqueta del género. De ahí, la prepotencia de lo masculino y la subalternidad de lo femenino. Son los ingredientes esenciales de ese orden simbólico que define las relaciones de poder de los hombres sobre las mujeres, origen de la violencia de género (...) Esa explicación de la violencia contra las mujeres en clave cultural, no biológica es la que define la perspectiva de género.

En este sentido, cuando se habla de roles de género, se hace referencia a las tareas, comportamientos, conductas, actitudes y formas de actuar que cada cultura espera o le asigna, históricamente, al hecho de ser hombre o mujer.

Los roles de género con el transcurso del tiempo ya no son vistos como tareas sino que se asumen como etiquetas o características propias del sexo, de lo que es ser hombre o mujer, que pasan a ser aceptadas por el grupo social sin ningún tipo de cuestionamiento y se le atribuye el carácter de inmutable, inmodificable y propio del "orden natural" de las cosas, considerándose verdades que no necesitan ser comprobadas (Defensoría del Pueblo, 2012). Así se construyen los estereotipos de género.

Los estereotipos de género se pueden definir como la atribución de "características o papeles específicos a los hombres y mujeres de manera individual por la sola razón de su pertenencia al grupo de hombres o mujeres" (Universidad de Toronto y CEJIL, 2008). Se reconoce que los estereotipos de género afectan a hombres y mujeres, pero es más notorio en estas últimas ya que son discriminadas al afectar e incluso anular, el reconocimiento, ejercicio o disfrute de sus derechos humanos y libertades fundamentales sobre la base de la igualdad. Los estereotipos de género actúan, a su vez, como causa y consecuencia de la violencia contra las mujeres basada en género.

Entre los estereotipos de género atribuidos a las mujeres pueden mencionarse algunas de las siguientes características: dócil, pacífica, obediente, sensible, emotiva, virginal, delicada y femenina; como atributos propios de los hombres: fuerte, valiente, agresivo, dominante, proveedor y macho. Estos estereotipos presentes en la construcción de la identidad de las personas determinan relaciones de poder según las cuales se le atribuye menor valor a las actitudes consideradas propias de las mujeres. De esta manera, los hombres y mujeres que no se comportan conforme a las conductas que la 
sociedad espera de ellos o ellas según su género, son unos "desviados" o "desviadas", que atentan contra el orden establecido, contra el "orden natural" de las cosas, esto se puede evidenciar en el juicio que se realiza de hombres y mujeres trasgresores de la ley, quienes cometieron un hecho punible y a quienes no solo el Derecho Penal, sino la sociedad, en su conjunto, los juzga conforme a los comportamientos que se espera de ellos y ellas en función del género al cual pertenecen.

Los estereotipos de género están presentes en la construcción de la sexualidad, en el derecho a decidir sobre el cuerpo propio y en el derecho a una vida libre de violencia, constituyendo un obstáculo para el ejercicio de los derechos de las mujeres que no tienen control sobre su cuerpo, su sexualidad, o en general, sobre sus vidas porque carecen de autonomía para decidir, decidiendo por ellas las religiones, el Estado, el Derecho, la Medicina y, por supuesto, el hombre. Es por ello que un ejercicio efectivo de los derechos humanos para las mujeres implica la erradicación de los estereotipos de género que las mantienen en una situación de subordinación y de desventaja.

\section{Contexto general}

El Centro Penitenciario Región Centro Occidental (Uribana) está ubicado a 6 horas por carretera de la ciudad de Caracas, capital de la República Bolivariana de Venezuela, tiene una capacidad instalada para 890 reclusos, sin embargo, en octubre de 2007 había 1.254 personas procesadas y 369 personas sentenciadas ${ }^{1}$. Esto indica una sobrepoblación de aproximadamente 350 personas, con los problemas de hacinamiento, falta de salubridad y violencia que ello acarrea. Estas condiciones de vida atentan contra la dignidad de las personas, demostrando el incumplimiento por parte del Estado venezolano con lo establecido en el artículo 10 del Pacto Internacional de Derechos Civiles y Políticos² (PIDCP) (1966), tanto el numeral 1 que obliga a los Estados Partes a tratar humanamente a todas las personas privadas de libertad y con el respeto debido a la dignidad inherente al ser humano y el numeral 2.a. que establece la obligación de separar a los procesados y las procesadas de los condenados y las condenadas, salvo en casos excepcionales y, además, el trato de los procesados y las procesadas debe adecuarse a su situación de personas no condenadas.

De este número total de personas internas en Uribana, 92 eran mujeres: 57 procesadas, 30 penadas y 5 estaban en destacamento de trabajo lo que les permitía a estas últimas salir a trabajar todos los días y pernoctar en el Centro. Cabe destacar que, en principio, las instalaciones fueron diseñadas para albergar a hombres, pero al igual como

1 Información obtenida de la página Web del Ministerio del Poder Popular para Relaciones Interiores y Justicia http://www.mpprij.gob.ve/, fecha 16 de octubre de 2007.

2 Adoptado el 16 de diciembre de 1966, ratificado por Venezuela el 28 de enero de 1978 según Gaceta Oficial N. ${ }^{\circ} 2.146$. 
ocurre en otros centros de reclusión del país, se ha instalado un anexo femenino para las mujeres.

Hasta ahora solo existe en Venezuela un centro de reclusión exclusivo para mujeres, el Instituto Nacional de Orientación Femenina (INOF), sin embargo, existen catorce anexos femeninos dependientes de instituciones penitenciarias diseñadas para atender a la población de hombres privados de libertad.

Del total de mujeres privadas de libertad en Uribana, 53 reclusas (58\%) estaban condenadas o procesadas por la comisión de algún delito relacionado con drogas, bien sea distribución, tráfico, ocultamiento o transporte. En general, no se trata de jefas de carteles o narcotraficantes de gran envergadura, comúnmente constituyen el eslabón más débil y visible de esta actividad delictiva.

El incremento del número de mujeres procesadas y condenadas por delitos de drogas se ha convertido en una constante en la mayoría de los países de América Latina, Carmen Antony (2007), profesora y criminóloga chilena escritora de varios libros sobre este tema, explica que esto se debe al hecho de que se trata de una actividad que les permite seguir desarrollando los roles tradicionales de género: reproductivos y del cuidado del hogar, es decir, los roles de madre, esposa, abuela y ama de casa, ya que no es necesario desplazarse fuera de sus viviendas para realizarla, lo que les permite continuar con las labores domésticas y cuidando a los hijos, hijas, nietos y nietas.

Un hecho que vale la pena resaltar de las conversaciones con las reclusas es el referente al nivel socioeconómico y el grado de instrucción que poseen, quedando en evidencia que la mayoría son madres, de bajo nivel educativo y en condiciones de pobreza. Esto las coloca en una situación de exclusión y de falta de oportunidades que, si bien no justifican la infracción de la ley, sí constituye un factor clave a analizar en una política criminal que trabaje para el logro de una verdadera reinserción social; ser mujer pobre y estar privada de libertad no escapa de la criminalización de la pobreza que se observa en las cárceles venezolanas, donde la mayoría de la población pertenece a los estratos socioeconómicos más bajos, lo que refuerza la necesidad de deconstruir el discurso jurídico y criminológico, ya que no se busca las causas de esta criminalidad ni se toman las medidas necesarias para que las instituciones penitenciarias cumplan con su función de permitir la reinserción social y laboral de la persona que ha sido condenada por la comisión de un hecho punible, por el contrario, las cárceles y las situaciones de violencia extrema que se viven en ellas son escuelas de criminalidad que profundizan la situación de exclusión de las personas privadas de libertad.

De las escasas actividades que se desarrollan dentro de Uribana destinadas a 
las mujeres privadas de libertad y cuyo objetivo es contribuir con su inserción social y laboral una vez cumplida la condena, se puede observar que reproducen los roles de género y la división sexual del trabajo que se observa en la sociedad en su conjunto. Es así como los pocos talleres impartidos a las mujeres reclusas se refieren a labores manuales, repostería, cerámica, cursos de cocina, entre otros, que reflejan el desarrollo de actividades consideradas comúnmente como femeninas; por su parte, los talleres impartidos a los hombres son más variados e incluyen actividades como: construcción, electricidad, talabartería, latonería, carpintería, e incluso, en alguna época, informática ${ }^{3}$ (Montes, 2005).

Esta diferenciación en los cursos impartidos demuestra que los realizados por los hombres tienen mayor salida laboral, lo que podría significar mayores oportunidades de inserción laboral, mientras que los impartidos a las mujeres, que se relacionan con actividades desarrolladas en el ámbito doméstico, con poca salida laboral, reducen las posibilidades para estas de obtener en prisión una formación profesional que les permita obtener un trabajo remunerado e insertarse en la sociedad.

Esta visión de la división sexual del trabajo y de los roles de género es compartida por las personas privadas de libertad.

3 En uno de los motines que se dio en Uribana, los reclusos destruyeron las instalaciones destinadas a la escuela y los equipos informáticos existentes, desconocemos si actualmente ya se ha recuperado el espacio y si hay dotación de nuevos equipos.
En un estudio realizado relativo a la reinserción social de las mujeres privadas de libertad que estaban en Uribana, encontramos testimonios de hombres y mujeres que confirman lo señalado anteriormente. Un hombre de 24 años recluido, quien se desempeñaba como facilitador de la Misión Robinson ${ }^{4}$ y estudiante de Ingeniería Industrial en la universidad, ante la pregunta sobre las actividades de las mujeres en el penal respondió lo siguiente:

(...) el penal es grande pero ellas no salen de su anexo a trabajar, ellas trabajan ahí, no sé, será algunas lavarán, plancharán y harán comida para algunos compañeros internos, de resto no sé; debería existir algo.

Bueno, yo sé que hay una o dos que limpian porque el Anexo es pequeño y con eso se ganan unos supuestos beneficios, no beneficios económicos que no tienen ninguno (Montes, 2005, p.71).

En otra entrevista realizada a una mujer de 28 años de edad, sentenciada a 5 años de prisión, de los cuales había pagado 2, se le preguntó sobre las actividades que realizaban los hombres y las mujeres en el centro penitenciario, a lo que respondió:

Las actividades que nosotros (sic.) las internas realizamos aquí dentro del Anexo de Damas son muy pocas,

4 Se trata de un programa de alfabetización desarrollado por el gobierno venezolano con el fin de erradicar el analfabetismo en el país. 
una de ellas es lavar la ropa tanto a los funcionarios como a los internos, planchar, cocinar, hacer muñequitas de trapo para poder sobrevivir porque muchas de las internas que estamos aquí, no tenemos apoyo económico, puede haber apoyo familiar, pero no hay el apoyo económico, muchas veces nosotros nos ganamos la vida aquí dentro, como les expliqué, haciendo muñecas de trapo, pintando cuadros, vendiendo comida porque yo también vendo comida rápida, los hombres tienen más actividades que nosotros, ellos tienen más herramienta de trabajo que nosotros, trabajan artesanías, pinturas, tejen cestas, también su actividad en la empresa que hay en el Centro, que pertenece a la "Tamanaco", cosen pelotas ${ }^{5}$, hacen cantidades de cosas, ellos tienen más actividades que nosotras las mujeres (Montes, 2005, p. 85).

Otro factor poco analizado en relación con las mujeres privadas de libertad en las cárceles venezolanas es el relativo a las distintas manifestaciones de violencia por razón de género que deben soportar tanto de los reclusos hombres como de los agentes del Estado que, en principio, deben respetar y garantizar sus derechos $^{6}$. Esto responde a la posición

5 La interna se refiere a una empresa fabricante de pelotas de distintos tipos que contrata a reclusos hombres que cosen las pelotas en un lugar del centro, sin embargo, las mujeres reclusas no participan en estas labores, de esta manera se les niega la posibilidad de obtener algún ingreso mientras permanecen en el centro.

6 Cabe destacar que en la sentencia del 25 de noviembre de 2006, caso Castro Castro vs. Perú, la Corte Interamericana de Derechos de subordinación de las mujeres en relación con los hombres, al uso de la fuerza, las relaciones de poder históricamente desiguales y a la objetivación de las mujeres, que no son vistas como personas sino como cuerpos sobre los cuales los hombres pueden decidir, tema que será abordado en el siguiente aparte.

\section{Los derechos humanos de las muje- res privadas de libertad}

Desde hace más de dos décadas desde las Naciones Unidas y otros sistemas de protección de derechos humanos se ha señalado que la violencia contra las mujeres basada en género constituye la forma más extrema de discriminación y una violación de sus derechos humanos, atenta contra la dignidad de las personas, el derecho a la vida, a la libertad, a la seguridad y destruye las familias. Además, impide el adelanto pleno de las mujeres en el terreno

\footnotetext{
Humanos, aplicando por primera vez en una de sus sentencias la perspectiva de género expresó: "Con respecto al tratamiento que deben recibir las mujeres detenidas o arrestadas, el Alto Comisionado de las Naciones Unidas para los Derechos Humanos ha señalado que "no deben sufrir discriminación, y deben ser protegidas de todas las formas de violencia o explotación". Asimismo, ha indicado que las detenidas deben ser supervisadas y revisadas por oficiales femeninas y las mujeres embarazadas y en lactancia deben ser proveídas con condiciones especiales durante su detención. El Comité para la Eliminación de la Discriminación contra la Mujer ha señalado que dicha discriminación incluye la violencia basada en el sexo, "es decir, la violencia dirigida contra la mujer porque es mujer o que la afecta en forma desproporcionada", y que abarca "actos que infligen daños o sufrimientos de índole física, mental o sexual, amenazas de cometer esos actos, coacción y otras formas de privación de la libertad."
} 
político, social, educativo, económico y en cualquier ámbito del accionar humano en condiciones equiparables a las de los hombres.

Este tipo de violencia anula la autonomía personal de las mujeres y la posibilidad de desarrollar un proyecto de vida personal, además, al ser una manifestación de las relaciones de poder históricamente desiguales entre hombres y mujeres, coloca a estas últimas en una situación de dominio y subordinación, limitando, obstaculizando, o incluso, no reconociéndoles derechos, anulándolas como personas. De allí la magnitud e importancia que tiene una vida libre de violencia para las mujeres.

A los efectos de este trabajo se utilizará la definición de violencia contra la mujer consagrada en la Convención Interamericana para Prevenir, Sancionar y Erradicar la Violencia contra la Mujer (Convención de Belem Do Pará, 1994) ${ }^{7}$, que la define como: "cualquier acción o conducta, basada en su género, que cause muerte, daño o sufrimiento físico, sexual o psicológico a la mujer, tanto en el ámbito público como en el privado" (artículo 1).

De esta manera, la Convención Belem Do Pará hace referencia a la violencia basada en género, por el hecho de ser mujer, que puede ser cometida por cualquier persona, no solamente en el marco

7 Aprobada por la Asamblea General de la OEA el 9 de junio de 1994, entrando en vigor el 05 de marzo de 1995. Ratificada por Venezuela el 16 de enero de 1995 según Gaceta Oficial N. ${ }^{\circ} 35.632$. de una relación de pareja, sino por cualquier hombre, incluyendo la violencia contra las mujeres que sea perpetrada o tolerada por el Estado o sus agentes, donde quiera que ocurra. Esto incluye la violencia que sufren las mujeres privadas de libertad, lo que desafortunadamente se constituye en una práctica común en los recintos penitenciarios.

Los abusos sexuales cometidos dentro de las cárceles se constituye en uno de los aspectos más violatorio de los derechos humanos de las mujeres privadas de libertad (Antony, 2003), supone el incumplimiento de una obligación fundamental para los Estados ya que su responsabilidad en el respeto y garantía de los derechos de estas mujeres es aún mayor, en un Estado de Derecho que debería tutelar el respeto a su dignidad como personas que cumplen una condena o están siendo procesadas por la presunta comisión de un hecho punible.

Señala Aponte (2002) que la mujer reclusa inicia su encuentro con la violencia institucional, aquella que es cometida o tolerada por agentes del Estado, desde el momento que se le imputa un hecho punible. Es así que la privación preventiva de libertad solicitada por el fiscal del Ministerio Público y acordada por el juez o la jueza de control (cuando no se trate de flagrancia), en oportunidades va acompañada de la violencia física o psicológica.

La Ley Orgánica sobre el Derecho de las Mujeres a una Vida Libre de Violencia, promulgada en 2007, define y 
tipifica en su artículo 15.16 la Violencia Institucional como:

(...) las acciones u omisiones que realizan las autoridades, funcionarios y funcionarias, profesionales, personal y agentes pertenecientes a cualquier órgano u ente público que contrariamente al debido ejercicio de sus atribuciones, retarden, obstaculicen o impidan que las mujeres tengan acceso a las políticas públicas y ejerzan los derechos previstos en esta Ley, para asegurarles una vida libre de violencia.

Las mujeres privadas de libertad no son solo víctimas invisibles del sistema penitenciario que las discrimina de múltiples maneras, sino además, los funcionarios que, en principio, están obligados a resguardarle sus derechos, los violan impunemente y se legitima un orden según el cual estas mujeres no merecen ser consideradas como personas titulares de derechos y son tratadas como escoria social, constituyéndose el delito de violencia institucional.

Las cárceles pueden ser lugares donde las reproducciones de los roles de género coloquen a las mujeres reclusas en situaciones de vulnerabilidad particularmente graves que las hacen víctimas potenciales de la violencia basada en género, incluida la violencia institucional cometida por funcionarios del Estado tales como custodios, guardias nacionales, entre otros.

En relación con los roles de género, desde la posición de los reclusos, en las cárceles se observan aquellos caracteres que "deben" poseer los hombres, a saber: fuerza, valentía, arrojo, agresividad, violencia, entre otros, para ser respetados y considerados como tales, ello incluye el control y dominio sobre las mujeres. Mostrarse agresivos y violentos pueden ser elementos que les otorguen cierto prestigio dentro del penal, e incluso, al salir de este de recinto. Mientras que los roles de género se expresan en relación con las internas en la percepción como mujeres "malas" que no han cumplido con su rol de cuidado de los hijos y las hijas y abandonando el trabajo doméstico, lo que puede originar el olvido y abandono por sus familias que agrava la pena impuesta. Como señala Marcela Lagarde (1993) esto lleva a que la prisión puede tener distintas significaciones para hombres y mujeres, para estas el haber estado en prisión las estigmatiza aún más y deben cargar con una culpa mayor, principalmente por haber sido "malas madres", maldad que se considera imperdonable e irreparable. Esta estigmatización de las reclusas está marcada por el hecho de haberse salido de su rol de género, de aquello que la sociedad espera de ellas, del estereotipo de la mujer buena, buena esposa, sumisa, obediente y cuidadora de sus hijos e hijas. Esto además explica las razones por las cuales la violencia puede agravarse según el tipo de delito cometido por las mujeres; cuando se trata del delito de infanticidio ("la mala madre") el trato es aún más denigrante que el recibido 
cuando se trata de un delito contra la propiedad (Aponte, 2002).

En el Estudio a fondo sobre todas las formas de violencia contra la mujer (2006), informe del Secretario General de las Naciones Unidas se afirma:

La violencia contra la mujer en situaciones de privación de libertad en celdas policiales, prisiones, instituciones de bienestar social, centros de detención de inmigración y otras instituciones del Estado constituye violencia cometida por el Estado. La violencia sexual, en particular la violación, cometida contra las mujeres detenidas se considera una violación particularmente flagrante de la dignidad intrínseca de los seres humanos y de su derecho a la integridad física, y consiguientemente pueden constituir tortura (Párrafo 141).

En este sentido, es preciso visibilizar esta forma extrema de violación de los derechos humanos de las mujeres privadas de libertad.

Lo dicho anteriormente sirve como marco de referencia para explicar ciertos acontecimientos sucedidos en Uribana que generaron violencia tanto para los hombres y las mujeres pero que se manifestaron de manera distinta en función del género: los internos del pabellón masculino tumbaron la cerca perimetral ${ }^{8}$ que separaba el ane-

8 Debido a los hechos relatados, se construyó una pared de cemento para separar el anexo femenino del pabellón de los hombres. xo femenino del pabellón y, a partir de ese hecho, hombres y mujeres convivieron en los mismos espacios, con la gravedad que los custodios o cualquier otro funcionario del Estado no podía entrar al pabellón masculino porque en ese recinto los internos tenían el control absoluto encontrándose armados con pistolas, granadas, escopetas, revólveres, lacrimógenas, entre otras armas. A partir de ese momento se establecieron parejas de reclusos y reclusas, pero también hubo violencia sexual hacia las internas.

En conversaciones con funcionarias judiciales del estado Lara, entidad en la cual se ubica Uribana, se pudo conocer el caso de una joven quien se presume era constantemente violada por los internos cuando estos lograron tumbar la valla que separaba el anexo femenino del resto del penal, lo que llevó a su defensora a solicitar una medida cautelar para poder sacarla de esa prisión y trasladarla a otro recinto. Sin embargo, no se abrió ninguna investigación para establecer la responsabilidad de los agresores. Y se trata de un fenómeno que no resulta excepcional ni aislado, sino que, por el contrario, está presente en la vida de las mujeres privadas de libertad, donde son cosificadas y agredidas de distintas formas, incluida la violencia sexual, pero no realizan denuncias por estos hechos por temor a ser castigadas, para evitar la estigmatización, e incluso, porque se acepta como parte de la condena impuesta. 
De esta forma, vemos como el Estado venezolano dejó de cumplir con las obligaciones establecidas en el artículo 7, literales a y b de la Convención Interamericana para Prevenir, Sancionar y Erradicar la Violencia contra la Mujer (1994), los cuales establecen la obligación de los Estados de "abstenerse de cualquier acción o práctica de violencia contra la mujer y velar por que las autoridades, sus funcionarios, personal y agentes e instituciones se comporten de conformidad con esta obligación", asimismo, se establece la obligación de "actuar con la debida diligencia para prevenir, investigar y sancionar la violencia contra la mujer".

A continuación se presenta el testimonio de una reclusa que relata por escrito su experiencia ante un motín ocurrido en el año 2004 en este mismo establecimiento penitenciario:

El 21 de septiembre a las 8:45 p.m los internos se han amotinado nuevamente contra los septores (sic.) vecinos fue una gran batalla que jamás en mi vida pensé que iba a vivir fue algo impresionante disparos granadas de todo se presentó ese día las mujeres solo temblábamos de miedo algunas lloraban sin parar, otras oraban y oraban, otras cantaban pero todas viviendo el mismo terror de lo sucedido eran las 11 p.m. cuando la Guardia y los funcionarios tuvieron compasión de nosotras y nos han sacado fuera del anexo a un sitio más seguro donde los hombres no pudieran llegar. Ya que decían iban en busca de las mujeres algunos dicen que para abusar físicamente de nosotras y otros dicen que para buscar seguridad y protección en nosotras (Montes, 2005, p. 129).

Estas situaciones pueden repetirse en otros centros penitenciarios de Venezuela y de América Latina como ha sido denunciado en reiteradas oportunidades por organizaciones defensoras de los derechos humanos.

Pero el derecho a una vida libre de violencia no es el único derecho conculcado a las reclusas, por el contrario, también se les han violado otros derechos tales como el derecho a la salud, a la integridad personal, a condiciones de vida dignas y los derechos sexuales.

En ese sentido, es preciso tener presente cuando se habla de personas privadas de libertad que siguen siendo titulares de derecho:

La persona privada de libertad, a consecuencia de una sanción penal condenatoria, posee un status jurídico particular: es sujeto titular de derechos fundamentales, pero el ejercicio de estos encuentra su límite en el fallo condenatorio, en el sentido de la pena, y en la propia situación de reclusión en que se halla. No obstante, la regla ha de ser el pleno reconocimiento, ejercicio y tutela de sus derechos fundamentales y garantías. La restricción de algunos de ellos, será la excepción (Rivera, citado por Morais, 2001, pp. 25-26). 
Podemos entonces inferir que el hombre o mujer que se encuentra privado de su libertad, es sujeto de derechos en las mismas condiciones en que están los que se encuentran en libertad y mas allá de los que la propia sentencia condenatoria les priva (libertad de tránsito fuera del establecimiento en que se encuentre, derechos políticos, inhabilitación civil, etc.), se encuentran en el pleno ejercicio de sus derechos fundamentales y el Estado por el mismo hecho de encontrase bajo su tutela jurídica, por su condición de privado de libertad, está en la obligación de satisfacerlos y garantizarlos (Nieto, 2010).

De las conversaciones con el director de Uribana, la consultora jurídica encargada del anexo femenino y un funcionario del establecimiento, se pudo tener conocimiento de varios hechos que atentan contra algunos derechos de las mujeres que no se pierden por estar privadas de libertad, por ejemplo, el derecho a la salud, consagrado en el artículo 12 del Pacto Internacional de Derechos Económicos, Sociales y Culturales, tratado del cual Venezuela es parte.

Las personas entrevistadas manifestaron que, si bien es cierto que en el Centro hay baños, la mayoría de ellos no funcionaban y tenían tapados los drenajes, lo que obligaba a los internos a defecar en las áreas verdes, lo que explicaba el mal olor existente en las instalaciones y evidencia los riesgos para la salud de las personas que allí habitan, que en el caso de las mujeres es aún más grave cuando tienen la menstruación y además por los peligros de contraer infecciones vaginales. Además, esto implica un incumplimiento de la Ley de Régimen Penitenciario $(2000)^{9}$ de Venezuela que establece que la higiene ambiental y la de las instalaciones, así como el aseo personal, entre otros elementos, son parte integrante de la finalidad última que es la reinserción social del penado o de la penada, lo que no se cumple en esta institución donde no existen las condiciones mínimas de higiene.

También se incumplen las Reglas Mínimas para el Tratamiento de los Reclusos de Naciones Unidas ${ }^{10}$ (1955) donde se señala que "Las instalaciones sanitarias deberán ser adecuadas para que el recluso pueda satisfacer sus necesidades naturales en el momento oportuno, en forma aseada y decente" (Regla 12).

La situación con el personal médico es bastante crítica. Según la versión oficial para el momento de la entrevista, había 1 psiquiatra y 2 médicos que trabajaban cada día 6 horas, sin embargo, existían dificultades para garantizarles la salud a las internas. Nos informó la consultora jurídica que había una mujer con HIV que no recibía el tratamiento especial con retrovirales porque el penal no contaba con este tipo de medicamentos

9 Gaceta Oficial 36.975 de fecha 19 de junio de 2000.

10 Adoptadas por el Primer Congreso de las Naciones Unidas sobre Prevención del Delito y Tratamiento del Delincuente, celebrado en Ginebra en 1955, y aprobadas por el Consejo Económico y Social en sus resoluciones 663C (XXIV) de 31 de julio de 1957 y 2076 (LXII) de 13 de mayo de 1977. 
y a diferencia de algunos reclusos hombres que también eran HIV positivos, a quienes sus familias les llevaban los medicamentos, en el caso de la reclusa, su familia estaba geográficamente muy distante de Uribana.

También constituye un obstáculo para la salud, la necesidad de una autorización por parte de los tribunales para trasladar a las reclusas para someterse a exámenes médicos o a tratamientos con especialistas, lo cual puede tardar un tiempo, tal era el caso de una mujer que padecía de la vesícula y estaba en la espera de la autorización para hacerse unos exámenes y someterse a una operación quirúrgica, o el de otra mujer de 58 años con recurrentes crisis de hipertensión. Estas trabas van en perjuicio de la atención integral de las mujeres, (por ejemplo, no reciben chequeos ginecológicos y nos encontramos con por lo menos 1 mujer con el virus del papiloma humano), y de lo establecido en la LRP que señala que en casos de alteraciones graves en la salud de un recluso o reclusa, el director o directora del penal deberá decidir de inmediato su traslado a un centro hospitalario para su atención, notificando posteriormente, dentro de las 24 horas siguientes esta decisión al tribunal de ejecución.

Otro hecho importante es el trato dado a las mujeres embarazadas, debido a que el Centro no cuenta con las condiciones mínimas para atender estos casos, estas son trasladadas al INOF, ubicado a 6 horas de este penal, lo que acarrea varias consecuencias, entre ellas, si se trata de una mujer que tiene otros hijos e hijas que viven en zonas cercanas al penal de Uribana, significa alejarla de su familia en un momento importante de su vida, ya que la distancia y el costo económico del traslado dificultaría que pueda recibir visitas en el INOF, pero además, en otros casos, después que la mujer tiene a su hijo o hija, la trasladan nuevamente al Centro de Uribana, separándola de su hijo o hija porque no existen las condiciones para tenerlo en este recinto, violando el artículo 75 de la Ley de Régimen Penitenciario (2000) que establece que las reclusas podrán conservar consigo a sus hijos o hijas menores de tres años, pudiendo ser prorrogado este lapso por el tribunal de protección de niños, niñas y adolescentes.

Estos son algunos ejemplos de las degradantes condiciones de vida de las mujeres privadas de libertad y de la violación de sus derechos humanos, lo que no se dice ni se denuncia porque estas condiciones quedan invisibilizadas y, en general, se conoce únicamente la situación de los hombres reclusos.

También se evidencia una marcada diferencia entre el trato recibido por los hombres y las mujeres privados y privadas de libertad en relación el ejercicio de los derechos sexuales y reproductivos, generándose una discriminación en contra de las mujeres que queda demostrada en los distintos parámetros usados para conceder la llamada "visita conyugal". A las mujeres se les exige el 
cumplimiento de los siguientes requisitos para poder disfrutarla:

1. Estar casadas o demostrar que se trata de un concubino estable.

2. Haber mantenido una conducta intachable durante el tiempo de reclusión.

3. Someterse a un examen médi$\mathrm{co}^{11} \mathrm{y}$ a las pruebas para detectar el HIV.

4. Es obligatorio el uso de un método anticonceptivo, las reclusas que se niegan a cumplir con esta medida no pueden gozar de las visitas conyugales, porque según las expresiones de funcionarios y funcionarias de centros penitenciarios entrevistados, las internas "no pueden quedar embarazadas".

Aunque no se señale expresamente, debe tratarse de relaciones heterosexuales, a las mujeres lesbianas se les niega absolutamente la posibilidad de recibir visitas conyugales de personas de su mismo sexo, lo que, incluso, es visto como una aberración por el personal de prisiones.

Según Posada y Díaz-Tremarias (2008), las visitas conyugales a las mujeres fueron reconocidas por la legislación venezolana en 1992, pero no fue sino hasta 7 años después, en 1999, que se incorporó como línea de trabajo la dotación de infraestructura para garantizarla, lo que aún en el año 2014 está lejos de lograrse porque siguen

11 No se especifica qué tipo de exámenes se les practican. siendo pocas las mujeres privadas de libertad a quienes se les autoriza estas visitas.

Hay que destacar que en algunos penales donde existen anexos femeninos, incluso, se les niega absolutamente las visitas conyugales a las mujeres mientras los hombres ejercen sus derechos sexuales sin ningún control ${ }^{12}$.

A los hombres internos en centros penitenciarios no se les exige el cumplimiento de ningún tipo de requisito para gozar del derecho a las visitas conyugales, siendo aún más evidente la discriminación en contra de las reclusas si tomamos en cuenta que en algunas de estas cárceles se permite la entrada de trabajadoras sexuales que mantienen relaciones con varios hombres los días de visitas sin que exista ningún tipo de control.

En Uribana solo 2 de las 92 internas disfrutaban de las visitas conyugales 2 horas cada 15 días, mientras que los hombres, según explicó el director del Centro, tenían visitas conyugales una vez a la semana, sin embargo, como las visitas de los hombres podían llegar hasta los dormitorios y estas eran tres veces a la semana, no se podía "controlar" si durante las visitas familiares los hombres tenían visitas conyugales.

12 Por ejemplo, en la Cárcel Nacional de Maracaibo donde los hombres sí tienen derecho a las visitas conyugales, mientras que a las mujeres se les niega (Aponte, 2002). 
En la Cuarta Conferencia Mundial sobre la Mujer (1995) se afirma que:

Los derechos humanos de la mujer incluyen su derecho a tener control sobre las cuestiones relativas a su sexualidad, incluida su salud sexual y reproductiva, y decidir libremente respecto de esas cuestiones, sin verse sujeta a la coerción, la discriminación y la violencia. Las relaciones igualitarias entre la mujer y el hombre respecto de las relaciones sexuales y la reproducción, incluido el pleno respeto de la integridad de la persona (Párrafo 96).

En este sentido, los derechos sexuales y reproductivos son derechos humanos, por tanto, el Estado está obligado a respetarlos, garantizarlos y satisfacerlos sin que se justifiquen diferencias basadas en el sexo o la identidad sexual de las personas.

La forma como el sistema penitenciario venezolano refuerza los roles y estereotipos de hombres y mujeres lleva a la invisibilización de las condiciones particulares de las mujeres privadas de libertad, negándoseles el derecho a las visitas conyugales o restringiéndoselas sin ningún tipo de fundamentación jurídica y además se les estigmatiza doblemente por delinquir y por ir en contra del modelo de mujer buena como se indicara. Dice Aponte (2002, p. 177) que: "Nuestra sociedad nos quiere santas, pero en la cárcel nos quiere también castas. En otras palabras, a la sanción legal le sigue una sanción moral solo por el hecho de ser una mujer infractora".

Cabe destacar que el establecimiento de medidas mucho más rigurosas a las mujeres con la supuesta finalidad de prevenir embarazos no deseados en las reclusas, no es un criterio razonable y viene a profundizar la discriminación fundada en el género debido a que solo las mujeres pueden estar sujetas a esta condición, lo que va en contra de lo establecido en el preámbulo de la Convención Internacional para la Eliminación de Todas las Formas de Discriminación contra la Mujer ${ }^{13}$ (CEDAW por sus siglas en inglés) (1979) donde se expresa que "El papel de la mujer en la procreación no debe ser causa de discriminación", y además significa una intervención de los agentes estatales en la intimidad de la vida de las reclusas, derecho al cual no priva la sentencia condenatoria, violando el derecho que estas tienen a decidir libremente el número de hijos e hijas que desean tener, derecho que no se suspende por estar la mujer privada de libertad, conforme a lo dispuesto en el artículo 16. $\mathrm{e}^{14}$ de la CEDAW (1979).

13 Adoptada el 18 de diciembre de 1979, entrando en vigor el 3 de septiembre de 1981, ratificada por Venezuela el 02 de mayo de 1983.

14 Artículo 16: "1. Los Estados Partes adoptarán todas las medidas adecuadas para eliminar la discriminación contra la mujer en todos los asuntos relacionados con el matrimonio y las relaciones familiares y, en particular, asegurarán en condiciones de igualdad entre hombres y mujeres: e) Los mismos derechos a decidir libre y responsablemente el número de sus hijos y el intervalo entre los nacimientos y a tener acceso a la información, la educación y los medios que les permitan ejercer estos derechos...". 
En este sentido, el Comité CEDAW recomienda a todos los Estados Partes que "...todos los servicios de salud sean compatibles con los derechos humanos de la mujer, inclusive sus derechos a la autonomía, intimidad, confidencialidad, consentimiento y opción con conocimiento de causa".

Obligar a las mujeres reclusas a usar algún método anticonceptivo en contra de su voluntad viola estos derechos y no es negándoles el uso de ellos, sino mediante programas encaminados a lograr el ejercicio de una sexualidad responsable, la manera como estos deben tutelarse.

Tampoco existe proporcionalidad entre la medida de exigir mayores requisitos a las mujeres para optar a las visitas conyugales y la finalidad perseguida, evitar las enfermedades de transmisión sexual y los embarazos, porque los reclusos hombres a quienes no se les exige el cumplimiento de estas formalidades también pueden contraer enfermedades sexuales y pueden fecundar dejando a las mujeres que los visitan embarazadas.

El trato diferenciado en este caso es discriminatorio porque no persigue un fin legítimo; que las reclusas sean sometidas a condiciones diferentes a los reclusos no busca lograr una igualdad efectiva de los derechos de las mujeres, ni tampoco se trata de una diferencia que se justifique porque hombres y mujeres estén en condiciones de desigualdad, por el contrario, la medida profundiza la discriminación de las mujeres, se basa en patrones socioculturales que, repetimos, estigmatizan doblemente a las mujeres: por delinquir y por ser "malas", teniendo deseos "propios" de los hombres y al adoptar este tipo de decisiones, los agentes estatales, en este caso los funcionarios y las funcionarias encargados y encargadas de dirigir las prisiones violan el derecho que tienen las mujeres a que se respeta su dignidad humana, que no se pierde bajo ninguna circunstancia y a ser libre de toda forma de discriminación de acuerdo a lo establecido en los artículos 2, 3 y 26 del PIDCP (1966 ${ }^{15}$ ); los artículos 1, 2, 5 y 16 de la CEDAW (1979); el artículo 1 de la Convención Americana de Derechos Humanos (1969 $\left.{ }^{16}\right)$; los artículos 4.e (el derecho de todas las mujeres a igual protección ante la ley y de la ley) y 6 (el derecho de toda mujer a ser libre de toda forma de discriminación, y a ser valorada y educada libre de patrones estereotipados de comportamiento) de la Convención Interamericana para Prevenir, Sancionar y Erradicar la Violencia contra la Mujer ${ }^{17}$ (Convención Belém do Pará) (1994).

15 Entró en vigor el 23 de marzo de 1976, de conformidad con el artículo 49.

16 Adoptada por la Asamblea General de la OEA el 22 de noviembre de 1969, entrando en vigor el 18 de julio de 1978. Ratificada por Venezuela el 14 de julio de 1977 según Gaceta Oficial N. ${ }^{\circ}$ 31.256.

17 Aprobada por la Asamblea General de la OEA el 9 de junio de 1994, entrando en vigor el 05 de marzo de 1995. Ratificada por Venezuela el 16 de enero de 1995 según Gaceta Oficial N. ${ }^{\circ} 35.632$. 
Las diferencias establecidas entre reclusos y reclusas para gozar del derecho a las visitas conyugales, coloca al Estado venezolano en una situación de incumplimiento de las obligaciones contraídas al ratificar la CEDAW, ya que no cumple con su compromiso de abstenerse de incurrir en discriminación contra la mujer, de acuerdo a lo establecido en el artículo $2 . \mathrm{d}^{18}$ en virtud de que son agentes estatales quienes actúan de esta manera.

Se trata de una violación de derechos humanos generalizada porque afecta a la población de mujeres reclusa en Venezuela, aunque se trata de un hecho específico, la regulación para el otorgamiento de visitas conyugales, es inherente a la falta de garantía que tienen las mujeres para el ejercicio de sus derechos sexuales y reproductivos con el agravante de que se trata de mujeres privadas de libertad y el Estado tiene una obligación mayor de garantizarlos.

\section{Conclusiones}

La situación de las mujeres privadas de libertad en Venezuela es preocupante ya que sus derechos humanos son violados reiteradamente, con el

18 Artículo 2. "Los Estados Partes condenan la discriminación contra la mujer en todas sus formas, convienen en seguir, por todos los medios apropiados y sin dilaciones, una política encaminada a eliminar la discriminación contra la mujer y, con tal objeto, se comprometen a: d) Abstenerse de incurrir en todo acto o práctica de discriminación contra la mujer y velar por que las autoridades e instituciones públicas actúen de conformidad con esta obligación..." agravante de no ser visibles a la sociedad la situación en la que se encuentran porque se toma como referencia las experiencias de los hombres privados de libertad. Se precisa reiterar que la dignidad inherente a todas las personas no se puede eliminar y debe respetarse en todas las circunstancias, en este sentido, las mujeres reclusas nunca pierden su condición de personas y, por tanto, el Estado y sus agentes están obligados a garantizarles condiciones mínimas que les permitan vivir dignamente.

Es preciso realizar un análisis de género que permita evidenciar las necesidades, el acceso a bienes y el disfrute de los derechos humanos de las mujeres privadas de libertad deslastrándose de los estereotipos de género que las estigmatiza y criminaliza doblemente por ir en contra de lo que la sociedad espera de ellas como mujeres.

Estas consideraciones llevan a la necesidad de deconstruir no solo Derecho Penal androcéntrico que tiene al hombre como referente universal, sino también la Criminología y las políticas criminales que perpetúan la situación de exclusión; se precisa de una Criminología crítica con perspectiva de género que visualice necesidades, experiencias y situaciones de las mujeres y de los hombres. 


\section{Referencias}

Antony, C. (2007). Mujeres invisibles: las cárceles femeninas en América Latina. Nueva Sociedad, (208), 73-85.

. (2003). Violaciones de los derechos humanos de las mujeres privadas de libertad. En Panorama de la situación de las mujeres privadas de libertad en América Latina desde una perspectiva de género (pp. 75-88). México: Comisión de Derechos Humanos del Distrito Federal, Comisión Mexicana de Defensa y Promoción de los Derechos Humanos y Fundación para el Debido Proceso Legal. Recuperado de http://www.catedradh. unesco.unam.mx/webmujeres/biblioteca/ Violencia/Violencia\%20contra\%20las\%20 mujeres\%20privadas.pdf

Aponte, E. (2002). Las mujeres reclusas en la Cárcel Nacional de Maracaibo. Otras miradas, 2 (1), 38-48.

Arroyo, R. (2007). Derechos humanos de las mujeres en América Latina: un camino para la transformación cultural. Pensamiento jurídico feminista. Deconstruir el Derecho repensar el mundo, N. -3 .

Azaola, E. (2007). Género y justicia penal en México. En Almeda, E. \& Bodelón, E. (eds.). Mujeres y Castigo: Un enfoque socio-jurídico y de género, 67-82. Madrid: Editorial Dikinson.

Castells, C. (1996). Introducción. En Perspectivas feministas en teoría política. Barcelona: Editorial Paidós.

Cobo, R. (2008). El género en las ciencias sociales. En Laurenzo, P., Maqueda, M. y Rubio, A. (Coords.). Género, violencia y derecho, 49-59. Valencia: Tirant lo Blanch.
Cook, R., Dickens, B. y Fathalla, M. (2003). Salud reproductiva y derechos humanos: integración de la medicina, la ética y el derecho. Bogotá: Profamilia.

Montes, C. (2005). Reinserción social de mujeres privadas de libertad del Centro Penitenciario de la Región Centro Occidental de Uribana, Barquisimeto, Estado Lara. Tesis de Maestría en Desarrollo Integral de la Mujer no publicada, Universidad Centroccidental Lisandro Alvarado, Barquisimeto, Estado Lara, Venezuela. Recuperado de http:// bibmed.ucla.edu.ve/edocs_bmucla/textocompleto/TWA491M65r2005.pdf

Defensoría del Pueblo (2012). Recomendaciones para optimizar la recepción de denuncias de violencia contra las mujeres. Caracas: Autor y UNFPA.

OVP denuncia 289 muertos en cárceles en 2013 (2013, 31 de julio). Informe 21. Recuperado de http://informe21.com/ actualidad/ovp-denuncia-289-muertosen-carceles-en-lo-que-va-de-ano

Facio, A. (2009). Derecho a una vida libre de violencia, derechos reproductivos y la responsabilidad estatal. Ponencia presentada el 5 de marzo en San José, Costa Rica.

Femenías, M. (2002). El feminismo latinoamericano ante el desafío de las diferencias. Revista Debats, 2 (76), 56-65.

Labrada, V. (1998). Introducción a la teoría de los derechos humanos: Fundamento. Historia. Declaración Universal de 10.XII.1948. Madrid: Editorial Civitas.

Lagarde, M. (1999). Democracia Genérica. En Antología latinoamericana y del Caribe: mujer y género. Managua: Universidad Centroamericana (UCA). 
. (1993). Los cautiverios de las mujeres: madres, esposas, monjas, putas, presas y locas. San José: Programa Mujer, Justicia y Género, ILANUD.

Lorente, M. (2005). Violencia contra las mujeres y trato indigno. Entre la invisibilidad y la negación. Feminismo/s, $\mathrm{N}^{\circ} 6$, pp. 65-78.

Maqueda, M. (2006). La violencia de género. Entre el concepto jurídico y la realidad social. Revista Electrónica de Ciencia Penal y Criminología, N. $.08-02$, pp. 02:1-02:13. Recuperado de http://criminet.ugr.es/ recpc/08/recpc08-02.pdf

Morais, M. (2001). El Funcionamiento de los Tribunales de Ejecución del Circuito Judicial Penal del Área Metropolitana de Caracas. Caracas: Centro de Investigaciones Jurídicas, Universidad Central de Venezuela. Recuperado de http://w2.ucab.edu.ve/ tl_files/IIJ/recursos/tribunales.pdf

Nash, M. (2004). Mujeres en el mundo. Historia, retos y movimientos. Madrid: Alianza Editorial.

Naciones Unidas (2006). Estudio a fondo sobre todas las formas de violencia contra la mujer. Informe del Secretario General. A/61/122/ Add.1 Recuperado de http://www.cepal. org/mujer/noticias/paginas/1/27401/ InformeSecreGeneral.pdf

Naciones Unidas (1996). Declaración de Beijing y plataforma para la acción. IV Conferencia mundial sobre las mujeres. Beijing (China) septiembre 1995. Madrid: Ministerio de Asuntos Sociales, Instituto de la Mujer. Recuperado de http://www. un.org/womenwatch/daw/beijing/pdf/ Beijing\%20full\%20report\%20S.pdf
Posada, A. y Díaz Tremarias, M. (2008). Las cárceles y población reclusa en Venezuela. En Revista Española de Sanidad Penitenciaria, 10, 22-27. Recuperado de http:// scielo.isciii.es/pdf/sanipe/v10n1/04_especial.pdf

Programa Internacional sobre Derecho a la Salud Reproductiva y Sexual de la Universidad de Toronto y el Centro por la Justicia y el Derecho Internacional (2008). Aplicación ante la Corte Interamericana de Derechos Humanos. Campo Algodonero: Claudia Ivette González, Esmeralda Herrera Monreal y Laura Berenice Ramos Monárrez en contra de los Estados Unidos Mexicanos. Recuperado de http:// cejil.org/sites/default/files/amicus-campo-algodonero-espl.pdf

Programa Venezolano de Educación-Acción en Derechos Humanos (2012). Situación de los Derechos Humanos en Venezuela, Informe Anual Enero - Diciembre 2012. Caracas: Autor.

Programa Venezolano de Educación-Acción en Derechos Humanos (2008). Informe Anual octubre 2007/septiembre 2008. Situación de los derechos humanos en Venezuela. Caracas: Autor.

Rodríguez, M. (2004). Violencia contra las Mujeres Privadas de Libertad en América Latina. Recuperado de http://www. cejamericas.org/index.php/biblioteca/ biblioteca-virtual/doc_view/4213-womena-and-jail-institutions-in-latin-america-document-in-spanish.html

Rubin, G. (1986). El tráfico de mujeres: Notas sobre la "economía política" del sexo. Nueva Antropología. 8(30), 95-145. 
Salazar, T. (2007). Análisis sobre la delincuencia femenina por droga Centro Penitenciario Los Andes Mérida-Venezuela 2005 -2006. Capítulo Criminológico, 35(4), 521-537.
Scott, J. (1996). El género: una categoría útil para el análisis histórico. En Lamas, M. (Comp.). El género: la construcción cultural de la diferencia sexual (pp. 265-302). México: PUEG.

Recibido: 25/11/2014 • Aceptado: 2/3/2015 